\title{
PENGARUH MOTIVASI DAN KOMITMEN ORGANISASI TERHADAP PRESTASI
}

\section{KERJA PADA PT YOROZU AUTOMOTIVE INDONESIA DI KARAWANG}

\author{
${ }^{1}$ Finny Julinda \\ ${ }^{2}$ Edy Suswardji Nugroho \\ ${ }^{3}$ Anggi Pasca Arnu \\ Universitas Singaperbangsa Karawang
}

Prodi S1 Manajemen, Fakultas Ekonomi dan Bisnis, Universitas Singaperbangsa Karawang

finnyjulinda20@gmail.com

\begin{abstract}
This research was conduced on employees on PT Yorozu Automotive Indonesia in Karawang. The research method used in this research is descriptive and verification methods. The samples used were 115 employees with Purposive Sampling. The data analysis technique used are scale range analysis techniques and path analysis using the Method of Successive Interval (MSI), Microsoft Excel 2007 and SPSS 16. The results showed that motivation has a positive and significant effect on Work Performance of PT Yorozu Automotive Indonesia in Karawang and Organizational Comitment has a positive and significant effect on work Performance of PT Yorozu Automotive Indonesia in Karawang. motivation and Organizational Comitment has a simultan effect on work Performance of PT Yorozu Automotive Indonesia in Karawang
\end{abstract}

\section{Keyword: Motivation, organizational Comitment, Work Performance}

\begin{abstract}
ABSTRAK
Penelitian ini dilakukan pada karyawan di PT Yorozu Automotive Indonesia di Karawang Metode penelitian yang digunakan dalam penelitian ini adalah metode deskriptif dan verifikatif. Sampel yang digunakan sebanyak 115 orang karyawan dengan metode purposive sampling. Teknik analisis data yang digunakan yaitu teknik analisis rentang skala dan analisis jalur dengan menggunakan Method of Successive Interval (MSI), Microsoft Excel 2007 dan SPSS 16. Hasil penelitian menunjukan bahwa Motivasi berpengaruh positif dan signifikan terhadap Prestasi Kerja PT Yorozu Automotive Indonesia di Karawang dan Komitmen Organisasi berpengaruh positif dan signifikan terhadap Prestasi Kerja PT Yorozu Automotive Indonesia di Karawang. Motivasi dan Komitmen Organisasi berpengaruh secara simultan terhadap Prestasi kerja PT Yorozu Automotive Indonesia di Karawang.
\end{abstract}

\section{Kata Kunci: Motivasi, Komitmen Organisasi, Prestasi Kerja}




\section{PENDAHULUAN}

Sumber daya manusia merupakan suatu asset utama yang besar pengaruhnya terhadap kemajuan organisasi. Seperti diketahui selama ini, organisasi lebih banyak menghadapi masalah-masalah yang berhubungan dengan sumber daya manusia apabila dibandingkan dengan sumber daya ekonomi lainnya, karena dalam mengelola sumber daya manusaia tidak bias disamakan dengan mesin, material, dan dana yang sifatnya hanya masalah teknis saja. Hal ini menjadi suatu masalah yang cukup rumit, sehingga organisasi mengalami kesulitan dalam menetapkan kebijakan terutama yang berhubungan dengan sumber daya manusia.

Tinggi rendahnya kualitas sumber daya manusia kini dialami berbagai organisasi baik perusahaan maupun non perusahaan, dan ternyata untuk mendapatkan sumber daya manusia yang benar-benar profesionla tidaklah mudah. Sumber daya manusia yang bekerja secara professional akan berdampak pada tinggi rendahnya prestasi kerja organisasi atau perusahaan tersebut. Tinggi rendahnya prestasi kerja karyawan dalam suatu organisasi atau perusahaan itu akan sangat berpengaruh terhadap upaya organisasi atau perusahaan dalam mencapai tujuannya. Dalam pencapaian tujuan dalam suatu organisasi, masalah pengelolaan karyawan sudah menjadi hal yang umum. Tidaklah wajar jika banyak karyawan yang sebenarnya secara potensi berkemampuan tinggi tetapi tidak berprestasi dalam kerja. Hal ini dimungkinkan karena rendahnya komitmen atau mungkin karena kurangnya motivasi dari tiap karyawannya ataupun dari atasannya. Jika hal ini dibiarkan terus menerus, maka sangatlah mungkin akan menurunkan prestasi kerja dari karyawan tersebut.

Menciptakan strategi untuk memotivasi karyawan dan membangun komitmen karyawan terhadap organisasi adalah factor penting untuk meningkatkan prestasi kerja karyawan. Adanya motivasi dan komitmen yang dimiliki karyawan akan berdampak positif terhadao kebutuhan mereka untuk memperoleh prestasi kerja. Seseorang ingin memperoleh prestasi kerja akan mendorong dirinya untuk mencintai pekerjaannya dan merasa memiliki atas pekerjaannya dan setia terhadap pekerjaan dan perusahaan. Rasa memiliki dan setai atas pekerjaan adalah suatu bentuk komitmen kerja dari dalam diri karyawan. Prestasi kerja dapat menjadi tolak ukur terhadap motivasi dan komitmen karyawan dalam sebuah perusahaan.

Oleh karena prestasi kerja merupakan hasil kerja secara kualitas dan kuantitas yang dicapai oleh karyawan dalam melaksakan tugasnya sesuai dengan tanggung jawab yang 
diberikan. Prestasi kerja pada PT Yorozu Automotive Indonesia menggunakan system yang disebut dengan Lembar Evaluasi Karyawan, dari hasil penilaian prestasi kerja tersebut dapat menunjukan tingkat prestasi kerja yang semakin tinggi ataupun sebaliknya semakin rendah. Dari hasil prestasi kerja dapat diketahuia manakah karyawan yang memiliki prestasi kerja yang tinggi dan karyawan yang memiliki prestasi kerja rendah. Adapun data yang diperoleh penulis mengenai prestasi kerja karyawan PT Yorozu Automotive Indonesia dalam mematuhi, melaksanakan, dan menyelesaikan tugasnya dari tahun 2017, 2018, dan 2019 adalah sebagai berikut:

Tabel 1.1

Daftar Penilaian Prestasi Kerja Tahun 2017 - 2018 - 2019

PT Yorozu Automotive Indonesia

\begin{tabular}{|c|c|c|c|c|c|c|c|c|c|c|}
\hline \multicolumn{3}{|c|}{ Jumlah Pegawai } & \multicolumn{6}{|c|}{$\begin{array}{c}\text { Hasil Peniliain Prestasi Kerja } \\
\text { Karyawan }\end{array}$} & \multirow{2}{*}{\multicolumn{2}{|c|}{$\begin{array}{l}\text { Kriteria dan } \\
\text { Keterangan }\end{array}$}} \\
\hline \multirow{5}{*}{84} & \multirow{5}{*}{84} & \multirow{5}{*}{84} & \multicolumn{2}{|c|}{2017} & \multicolumn{2}{|c|}{2018} & \multicolumn{2}{|c|}{2019} & & \\
\hline & & & $\begin{array}{l}95- \\
100\end{array}$ & 3 & $95-100$ & $\begin{array}{l}3 \\
7\end{array}$ & $\begin{array}{l}95- \\
100\end{array}$ & 16 & $\begin{array}{l}95- \\
100\end{array}$ & $\begin{array}{c}\text { 1G+1R } \\
\text { UP }\end{array}$ \\
\hline & & & $\begin{array}{c}90- \\
94\end{array}$ & 4 & $90-94$ & $\begin{array}{l}1 \\
8\end{array}$ & $90-94$ & 15 & $90-94$ & $1 G \mathrm{UP}$ \\
\hline & & & $\begin{array}{c}80- \\
89\end{array}$ & $\begin{array}{l}6 \\
5\end{array}$ & $80-89$ & $\begin{array}{l}1 \\
9\end{array}$ & $80-89$ & 28 & $80-89$ & 2R UP \\
\hline & & & $\begin{array}{c}70- \\
79\end{array}$ & $\begin{array}{l}1 \\
2\end{array}$ & $70-79$ & $\begin{array}{l}1 \\
0\end{array}$ & $70-79$ & 25 & $70-79$ & 1R UP \\
\hline
\end{tabular}

Sumber: HRD PT Yorozu Automotive Indonesia, 2019

Dari tabel di atas hasil penilaian prestasi kerja karyawan pada PT Yorozu Automotive Indonesia terlihat pada tahun 2017 jumlah pegawai sebanyak 84 orang yang mendapatkan kenaikan 1 Grada dan 1 Range sebanyak 3 orang, sebanyak 4 orang mendapatkan kenaikan 1 Grade, sebanyak 65 orang mendapatkan kenaikan 2 Range, dan sebanyak 12 orang mendapatkan kenaikan 1 Range. Pada tahun 2018 dengan jumlah 84 orang mendapatkan kenaikan 1 Grade dan 1 Range sebanyak 37 orang, sebanyak 18 mendapatkan kenaikan 1 Grade, sebanyak 19 orang mendapatkan kenaikan 2 Range, dan mendapatkan kenaikan 1 Range sebanyak 10 orang. Pada tahun 2019 dengan jumlah pegawai 84 orang mendapatkan kenaikan 1 Grade dan 1 Range sebanyak 16 orang, sebanyak 15 orang mendapatkan kenaikan 
1 Grade, sebanyak 28 orang mendapatkan kenaikan 2 Range, dan yang mendapatkan kenaikan 1 Range banyak 25 orang. Dari hasil tersebut dapat diketahui bahwa prestasi kerja pada PT Yorozu Automotive Indonesia tidak stabil atau terjadinya kenaikan dan penurunan pada prestasi kerja karyawan.

\section{KAJIAN PUSTAKA}

\section{Manajemen Sumber Daya Manusia}

Manajemen Sumber Daya Manusia (MSDM) merupakan bidang startegis dari organisasi. Manajemen sumber daya manusia sangat penting bagu general manajer di semua bagian atau departemen agar dapat diterapkan dengan benar dan tepat sehingga mampu memaksimalkan potensi karyawan dalam rangka meningkatkan akselerasi kinerja perusahaan serta menghadapi tantangan globalisasi, seperti MEA.

Menurut Arif Yusuf Hamali (2016:6) bahwa manajemen sumber daya manusia merupakan proses serta upaya untuk merekrut, mengembangkan, memotivasi, serta mengevaluasi keseluruhan sumber daya manusia yang diperlukan perusahaan dalam pencapaian tujuannya.

\section{Motivasi}

Motivasi memegang peranan sangat penting dalam menentukan keberhasilan seseorang dalam melaksanakan tugas yang dibebankan kepadanya. Motivasi bukanlah sesuatu yang dapat diamati, trtapi merupakan sesuatu yang dapat terlihat melalui perilaku yang diperlihatkan oleh individu yang bersangkutan. Tiap kegiatan yang dilakukan oleh sesorang didorong oleh sesuatu kekuatan dari dalam diri orang tersebut, kekuatan pendorong ini lah yang disebut motivasi.

Menurut Hasibuan (2011:141) motivasi adalah pemberian daya penggerak yang menciptakan kegairahan kerja seseorang, agar mereka mau bekerja sama secar produktif berhadap mencapai dan mewujudkan tujuan yang telah ditentukan.

Menurut Abraham Maslow dalam A.A. Anwar Prabu Mangkunegara (2017: 101) dimensi dari motivasi adalah sebagai berikut:

1. Kebutuhan Fisiologis, yaitu kebutuhan makan, minum, perlindungan fisik, bernafas, dan sexual. Kebutuhan ini merupakan kebutuhan yang paling mendasar. 
Dalam hubungan dengan kebutuhan ini pemimpin perlu memberikan gaji yang layak kepaa pegawai.

2. Kebutuhan rasa aman, yaitu kebutuahn perlinungan dari ancaman bahaya, dan lingkungan kerja. Dalam hubungan dengan kebutuhan ini pemimpin perlu memberikan tunjangan kesehatan, asuransi kecelakaan, perumahan, dan dana pensiun.

3. Kebutuah sosial atau rasa ingin memiliki, yaitu kebutuhan unyuk diterima dalam kelompok unit kerja, berafiliasi, berinteraksi, serta rasa dicintai dan mencintai. Dalam hubungan dengan kebutuhan ini, pemimpin perlu menerima eksitensi/keberadaan pegawai sebagai angota kelompok kerja, melakukan interaksi kerja yang baik dan hubungan kerja yang harmonis.

4. Kebutuhan harga diri, yaitu kebutuhan untuk dihormati, dihargai oleh orang lain. Dalam hubungan dengan kebutuhan ini, pemimpin tidak boleh sewenang-wenang memperlakukan pegawai karena perlu dihormati, diberi penghargaan terhadap prestasi kerjanya.

5. Kebutuhan aktualisasi diri, yaitu kebutuhan untuk mengembangkan diri dan potensi, mengemukakan ide-ide, memberikan penilaian, kritis dan berprestasi. Dalam hubungan dengan kebutuhan ini, pemimpin perlu memberi kesempatan kepada pegawai bahawan agar mereka dapat mengaktulisasikan diri secara baik dan wajar di perusahaan.

\section{Komitmen Organisasi}

Komitmen organisasi bisa tumbuh disebabkan karena individu memiliki ikatan emosional terhadap perusahaan yang meliputi dukungan moral dan menerima nilai yang ada di dalam perusahaan serta tekad dari dalam diri untuk mengabdi pada perusahaan.

Menurut Colquitt, Lepine, dan Wesson (2011: 9) dalam Wibowo (2017:430) komitmen adalah sebagai keinginan pada sebagian pekerja untuk tetap menjadi anggota oganisasi. Komitmen organisasional mempengaruhi apakah seorang pekerja tetap tinggal sebagai anggota organisasi (is retained) atau meninggalkan untuk mengejar pekerjaan lain (turnover).

Meyer an Allen dalam Khaerul Umam (2012: 259) mengemukakan tiga dimensi dalam komitmen organisasi, antara lain: 
1. Komitmen efektif (affictive commitment), yaitu perasaan emosional pada organisasi yang memunculkan kemauan untuk tetap tinggal dalam organisasi dan membina hubungan sosial serta menghargai nilai hubungan dengan organisasi dikarenakan keterlibatannya dengan organisasi tersebut.

2. Komitmen kontinyu (continuance commitment), yaitu perasaan berat untuk 6meninggalkan organisasi dikarenakan kebutuhan untuk bertahan dengan pertimbangan biaya apabila meninggalkan organisasi dan penghargaan yang berkenaan dengan keterlibatan diri di dalam organisasi. Hal ini mungkin disebabkan takut kehilangan promosi atau keuntungan-keuntungan lainnya karena lamanya bekerja.

3. Komitmen normatif (normative commitment), yaitu perasaan pekerja yang mengharuskan untuk bertahan dalam organisasi karena ia merasa harus dan itu adalah hal yang baik untuk dilakukannya. Hal ini disebabkan kewajiban dan tanggung jawab terhadap organisasi yang didasari atas pertimbangan norma, nilai, dan keyakinan karyawan terhadap organisasi.

\section{Prestasi Kerja}

Prestasi kerja merupakan salah satu kebutuhan manusia yang terpenting dan selalu ingin dicapai. Prestasi kerja merupakan keadaan dimana seseorang merasa bahwa dia telah berhasil dan dapat menyelesaikan pekerjaannya dan merasa bahwa hasil pekerjaannya itu merupakan kebutuhan orang lain.

Menurut Hasibuan dalam Badriah (2015:136), prestasi kerja adalah hasil kerja yang dicapai seseorang dalam melaksanakan tugas-tugas yang dibebankan kepadanya, yang didasarkan atas pengalaman kesungguhan dan waktu.

Menurut Edy Sutrisno (2014:152) pengukuran prestasi kerja diarahkan pada enam aspek yaitu:

1. Hasil Kerja, tingkat kualitas maupun kuantitas yang telah dihasilkan dan sejauh mana pengawan dilakukan.

2. Pengetahuan Pekerjaan, tingkat pengetahuan yang terkait dengan tugas pekerjaan yang akan berpengaruh langsung terhadap kuantitas dan kualitas hasil kerja.

3. Inisiatif, tingkat insiatif selama melaksanakan tugas pekerjaan khususnya instruksi kerja dan menyesuaikan dengan cara kerja serta situasi kerja yang ada. 
4. Kecekatan Mental, tingkat kemampuan dan kecepatan dalam meneriman instruksi kerja dan menyesuaikan dengan cara kerja serta situasi kerja yang ada.

5. Sikap, tingkat semangat kerja serat sikap positif dalam melaksanakan tugas pekerjaan.

6. Disiplin Waktu dan Absensi, tingkat ketepatan waktu dan tingkat kehadiran.

\section{METODELOGI PENELITIAN}

Metode Penelitian dalam penelitian ini menggunakan metode deskriptif dan verifikatif yaitu mengumpulkan, menyajikan, menganalisis dan melakukan pengujian hipotesis, serta membuat kesimpulan dan saran. Sampel dikumpulkan dengan menggunakan metode sampel purposive dengan sampel 115 responden. Teknik analisis data yang digunakan yaitu teknik analisis rentang skala dan analisis jalur dengan menggunakan Method of Successive Interval (MSI), Microsoft excel 2007 dan SPSS16.

\section{Instrumen Penelitian}

Tabel 3.1

\section{Instrumen Penelitian}

\begin{tabular}{|c|c|c|c|}
\hline Variabel & Sub Variabel & Indikator & $\begin{array}{c}\text { No } \\
\text { Pernyataan }\end{array}$ \\
\hline \multirow{12}{*}{$\begin{array}{l}\text { Motivasi } \\
\text { Kerja (X1) }\end{array}$} & \multirow[b]{2}{*}{ Kebutuhan Fisik } & 1. Pemberian Gaji & 1 \\
\hline & & $\begin{array}{l}\text { 2. Tunjangan Makan dan } \\
\text { Minum }\end{array}$ & 2 \\
\hline & \multirow{4}{*}{$\begin{array}{l}\text { Kebutuhan Rasa } \\
\text { Aman }\end{array}$} & 3. Tunjangan Kesehatan & 3 \\
\hline & & 4. Jaminan Tenaga Kerja & 4 \\
\hline & & 5. Tunjangan Pensiun & 5 \\
\hline & & 6. Lingkungan Kerja & 6 \\
\hline & \multirow{3}{*}{ Kebutuhan Sosial } & $\begin{array}{l}\text { 7. Hubungan dengan } \\
\text { Rekan Kerja }\end{array}$ & 7 \\
\hline & & $\begin{array}{l}\text { 8. Hubungan dengan } \\
\text { Atasan }\end{array}$ & 8 \\
\hline & & 9. Kerjasama Kelompok & 9 \\
\hline & \multirow{3}{*}{$\begin{array}{l}\text { Kebutuhan } \\
\text { Penghargaan }\end{array}$} & $\begin{array}{l}\text { 10. Pemberian Bonus atas } \\
\text { Produksi }\end{array}$ & 10 \\
\hline & & $\begin{array}{l}\text { 11. Pemberian } \\
\text { Penghargaan }\end{array}$ & 11 \\
\hline & & $\begin{array}{l}\text { 12. Kenaikan Gaji atas } \\
\text { Prestasi Kerja }\end{array}$ & 12 \\
\hline
\end{tabular}




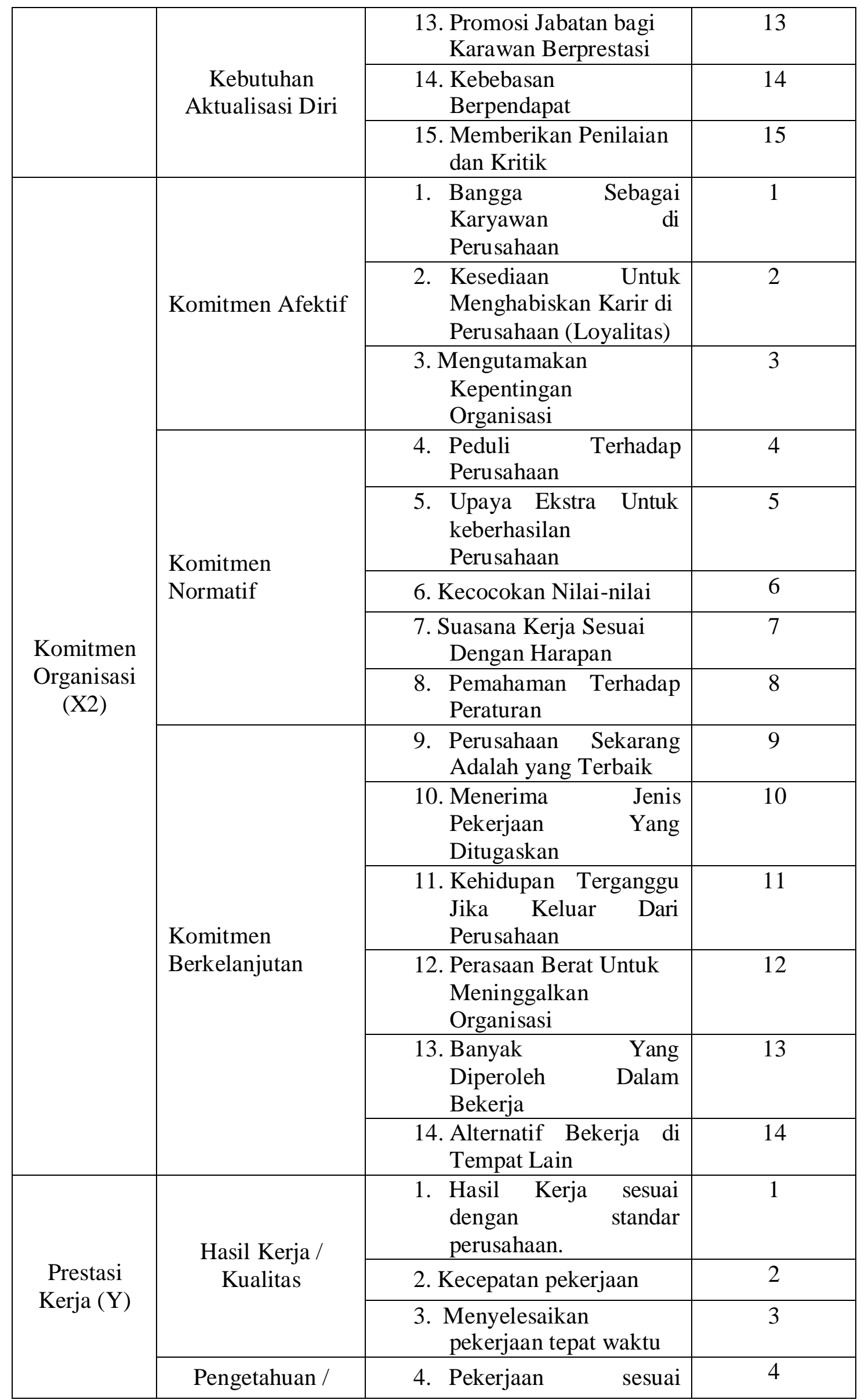




\begin{tabular}{|c|c|c|}
\hline \multirow[t]{4}{*}{ Kuantitas } & dengan target & \\
\hline & 5. Jumlah hasil pekerjaan & 5 \\
\hline & 6. Memilki keterampilan & 6 \\
\hline & $\begin{array}{l}\text { 7. Menyelesaikan } \\
\text { pekerjaan }\end{array}$ & 7 \\
\hline \multirow{3}{*}{ Inisatif } & 8. Kemandirian & 8 \\
\hline & $\begin{array}{l}\text { 9. } \begin{array}{l}\text { Bekerja tanpa } \\
\text { pengawasan }\end{array} \\
\end{array}$ & 9 \\
\hline & $\begin{array}{l}\text { 10. Mampu mengambil } \\
\text { keputusan }\end{array}$ & 10 \\
\hline Kecekatan Mental & $\begin{array}{l}\text { 11. Menerima intruksi } \\
\text { dengan baik }\end{array}$ & 11 \\
\hline Sikap & 12. Mampu bersikap baik & 12 \\
\hline \multirow{3}{*}{$\begin{array}{l}\text { Disiplin Waktu } \\
\text { dan Absensi }\end{array}$} & 13. Datang tepat waktu & 13 \\
\hline & $\begin{array}{l}\text { 14. Mematuhi peraturan } \\
\text { perusahaan }\end{array}$ & 14 \\
\hline & $\begin{array}{l}\text { 15. Keluar dan masuk } \\
\text { sesuai } \\
\text { peraturan. }\end{array}$ & 15 \\
\hline
\end{tabular}

\section{Metode Analisis Data}

\section{Analisis Jalur}

Path analysis adalah suatu teknik untuk menganalisis hubungan sebab akibat yang terjadi pada regresi berganda jika variable bebasnya mempengaruhi variable tergantung tidak hanya secara langsung, tetapi juga secara tidak langsung (Robert D. Retherford) dalam (Paradede san Munurung, (2014:2016). Path Analysis bermanfaat untuk menjelaskan (explanation) terhadap fenomena yang dipelajari atau permasalahan yang diteliti (Riduwan dan Sunarto, 2011:140).

Untuk besarnya pengaruh langsung dinyatakan koefisien jalur (path coefficient) lambangnya $\mathrm{p}$ dan besarnya keeratan hubungan antara variable dinyatakan oleh koefisien korelasi (r). berdasarkankajian teoritis dan uraian diatas yang melahirkan paradigm penelitian, maka untuk mempermudah pengujian statistika digambarkan diagaram jalur (path analysis) pada gambar sebagai berikut 


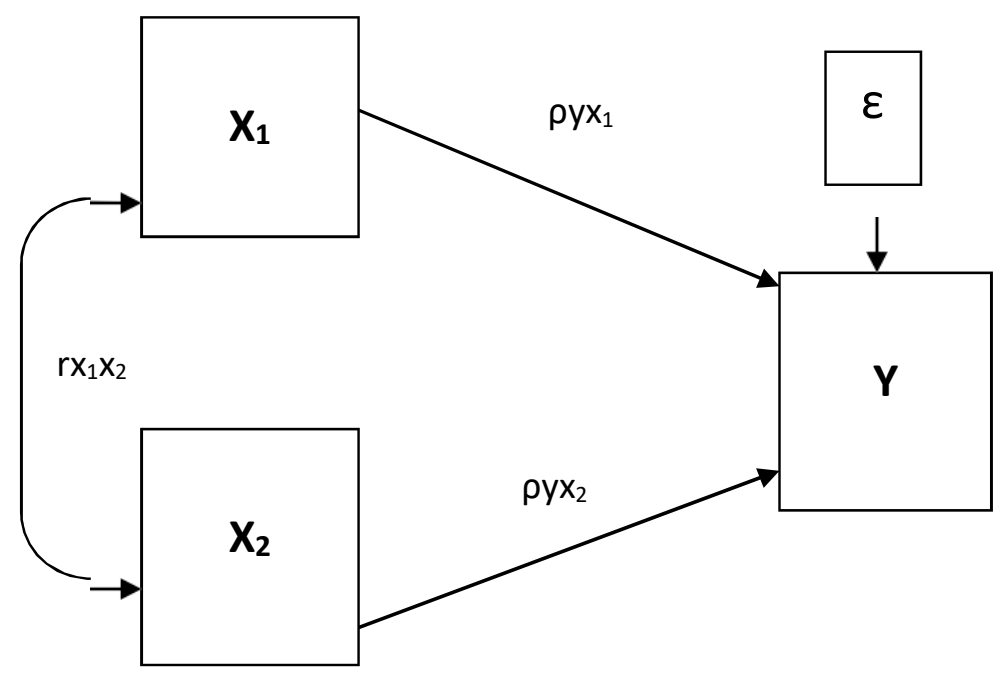

Gambar 3.3

Analisis Jalur

Sumber: Ridwan dan Kuncoro (2014:3)

Persamaan Struktural :

$Y=\operatorname{pyx}_{1} X_{1}+\operatorname{pyx}_{2} X_{2}+p y \varepsilon_{1}$

Keterangan :

$\mathrm{X} 1$

: Motivasi

$\mathrm{X} 2$

: Komitmen Organisasi

Y

: Prestasi Kerja

$\mathrm{rX}_{1} \mathrm{X}_{2}$

: Korelasi X1 dan X2

$\operatorname{pyx}_{1} x_{1}$

: Koefisien jalur yang menggambarkan besarnya pengaruh langsung $\mathrm{x}_{1}$ terhadap $\mathrm{Y}$

$\operatorname{pyx}_{2} \mathrm{x}_{2}$

: Koefisien jalur yang menggambarkan besarnya pengaruh langsung $\mathrm{X}_{2}$ terhadap $\mathrm{Y}$.

py $\varepsilon_{1}$

:Variabel lain yang tidak diukur, tetapi mempengaruhi Y. 


\section{Pengujian Hipotesis}

Uji hipotesis untuk mendeskripsikan ketigas variable penelitian secara statistic adalah sebagai berikut :

1. Kolerasi antara Motivasi dan Komitmen Orgniasasi (uji t)

Ho: $\mathrm{rX}_{1} \mathrm{X}_{2}=0 \quad$ Tidak terdapat korelasi antara Motivasi dengan Komitmen Organisasi.

Ho: $\mathrm{rX}_{1} \mathrm{X}_{2} \neq \quad$ Terdapat korelasi antara Motivasi dengan Komitmen Organisasi.

2. Pengaruh Parsial

a. Pengaruh Parsial Motivasi terhadap Prestasi Kerja (Uji t)

Ho: $\mathrm{pyx}_{1}=0 \quad$ Tidak terdapat pengaruh parsial antara Motivasi terhadap Prestasi Kerja.

Ho: $\operatorname{pyx}_{1} \neq 0 \quad$ Terdapat pengaruh parsial antara Motivasi terhadap Prestasi kerja.

b. Pengaruh Parsial Komitmen Organisasi terhadap Prestasi Kerja (Uji t)

Ho: $\operatorname{pyx}_{2}=0$ Tidak terdapat pengaruh parsial antara Komitmen Organisasi terhadap Prestasi Kerja.

Ho: $\operatorname{pyx}_{2} \neq 0 \quad$ Terdapat pengaruh parsial antara Komitmen Organisasi terhadap Prestasi kerja.

3. Pengaruh Simultan dari Motivasi (X1) dan Komitmen Organisasi (X2) terhadap Prestasi Kerja (Uji t)

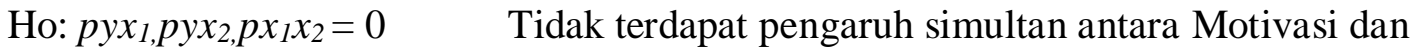
Komitmen Organisasi terhadap Prestasi Kerja.

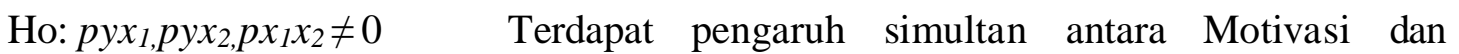
Komitmen Organisasi terhadap Prestasi Kerja.

\section{HASIL DAN PEMBAHASAN}

Penelitian ini dilakukan dengan mengambil sampel sebanyak 115 karyawan PT Yorozu Automotive Indonesia di Karawang. Gambaran karyawan menujukan mayoritas berusia 26-30 tahun dengan persentase sebesar 44,3\%. Dengan laki - laki sebanyak 108 
orang sedangkan perempuan sebanyak 7 orang. Diketahui juga karyawan yang bekerja di PT Yorozu Automotive Indonesia di Karawang menyelesaikan pendidikannya pada jenjang SMA/SMK sebesar 92,2\%.

\section{Korelasi Motivasi dengan Komitmen Organisasi}

Kolerasi antara Motivasi dengan Komitmen Organisasi memiliki nilai koefisien kolerasi sebesar 0,650 artinya mempunyai hubungan yang kuat dan searah karena nilainya positif dan berada pada interval koefisien 0,60 - 0,799 dengan kategori kuat.

\section{Koefisien Jalur Motivasi (X1) terhadap Prestasi Kerja (Y)}

Pengaruh Motivasi terhadap Prestasi Kerja memiliki nilai sebesar 0,446. Dengan demikian motivasi memiliki pengaruh sebesar 44,6\% terhadap prestasi kerja. Hal ini menunjukan bahwa koefisien jalur variabel motivasi (x1) terhadap variabel prestasi kerja (Y) sehingga diperoleh persamaan $\mathbf{Y}=\mathbf{0 , 4 4 6} \mathbf{X}_{\mathbf{1}}$

\section{Koefisien jalur Variabel Komitmen Organisasi (X2) Terhadap Variabel Prestasi Kerja} (Y)

Pengaruh komitmen organisasi terhadap prestasi kerja adalah sebesar 0,453. Dengan demikian komitmen organisasi memiliki pengaruh sebesar 45,3\% terhadap prestasi kerja. Hal ini menunjukan bahwa koefisien jalur variabel komitmen organisasi (x2) terhadap variabel prestasi kerja (Y) sehingga diperoleh persamaan $\mathbf{Y}=\mathbf{0 , 4 5 3}$ X2

\section{Pengaruh Motivasi dan Komitmen Organisasi terhadap Prestasi Kerja}

Pengaruh simultan motivasi dan komitmen organisasi terhadap prestasi kerja, dengan kriteria uji nilai Sig. $(0,000)<\alpha \quad(0,05)$, dan $f_{\text {hitung }}(112,114)>f_{\text {tabel }} \quad(4,79)$ maka $\mathrm{H}_{\mathrm{o}}$ ditolak. Total pengaruh motivasi dan komitmen organisasi terhadap prestasi kerja sebesar sebesar 53,4\% sedangkan sisanya 46,6\% variable lain (ع) yang tidak diteliti. 


\section{KESIMPULAN}

Berdasarkan hasil penelitian, pengumpulan data dan pembahasan yang dilakukan peneliti pada PT Yorozu Automotive Indonesia, maka dapat di ambul kesimpulan sebagai berikut:

1. Berdasarkan hasil penelitian bahwa motivasi pada PT Yorozu Automotive Indonesia berdasarkan hasil kuesioner diperoleh skor rata-rata 362 yaitu berada pada rentang skala 299 - 391 dengan kriteria cukup setuju. Namun terdapat indicator dengan nilai terendah yaitu kerjasama kelompok dengan skor 373. Dan didapatkan nilai tertinggi yiatu indicator kenaikan gaji atas prestasi kerja dengan skor 427 ..

2. Berdasarkan hasil penelitian bahwa komitmen organisasi pada PT Yorozu Automotive Indonesia berdasarkan hasil kuesioner diperoleh skor rata-rata 387 yiatu berada pada rentang skala 299 - 391 dengan kriteria cukup setuju. Namun terdapat indicator dengan nilai terendah yaitu menerima jenis pekerjaan yang ditugaskan dengan skor 354. Dan didapatkan nilai tertinggi yaitu indicator suasana kerja sesuai dengan harapan dengan skor 413.

3. Berdasarkan hasil penelitian bahwa prestasi kerja pada PT Yorozu Automotive Indonesia berdasarkan hasil kuesioner diperoleh skor rata-rata 413 yaitu berada pada rentang skala 391 - 483 dengan kriteria setuju. Namun terdpat indicator dengan nilai terendah yaitu pekerjaan sesuai dengan target dengan skor 390. Dan didapatkan nilai tertinggi yaitu indicator mematuhi peraturan perusahaan dengan skor 434 .

4. Korelasi antara variabel bebas yaitu motivasi dan komitmen organisasi menunjukan kolerasi sebesar 0,650 artinya mempunyai korelasi yang kuat, positif, dan signifikan. Hal ini menunjukan bahwa motivasi dapat meningkatkan komitmen organisasi pada PT Yorozu Automotive Indonesia begitu juga sebaliknya.

5. Terdapat pengaruh parsial motivasi dan komitmen organisasi terhadap prestasi kerja .

a. Terdapat pengaruh motivasi terhadap prestasi kerja sebesar 0, 329 atau 32,9\%. Hal ini menunjukan bahwa motivasi memiliki pengaruh terhadap prestasi kerja pada PT Yorozu Automotive Indonesia.

b. Terdapat pengaruh komitmen organisasi terhadap prestasi kerja sebesar 0, 336 atau 33,6\%. Hal ini menunjukan bahwa komitmen organisasi memiliki pengaruh terhadap prestasi kerja. 
6. Terdapat pengaruh simultan motivasi dan komitmen organisasi terhadap pestasi kerja pada PT Yorozu Automotive Indonesia sebesar 0,534 atau 53,4\% sedangkan sisanya 0,446 atau 44,6\% merupakan pengaruh variabel lain $(\varepsilon)$ yang tidak diteliti. Hal ini menunjukan bahwa motivasi dan komitmen organisasi secara bersama-sama memiliki pengaruh terhadap prestasi kerja pada PT Yorozu Automotive Indonesia.

\section{Saran Bagi Perusahaan}

1. Perusahaan dapat terus memberikan motivasi dengan cara perlunya memberikan kompensasi ataupun gaji yang sesuai kepada karyawan, selain itu perlunya peningkatan insentif atau bonus pada karyawan bekerja di luar jam kerjanya.

2. Perusahaan lebih mengoptimalkan pemberian motivasi terhadap karyawan, dengan cara seperti melakukan motivasi berkala, pemberian pelatihan, dan memperbaikin kesejahteraan karyawan.

3. Perusahaan diharapkan lebih mengembangkan budaya organisasi yang ada di perusahaan, dengan adanya budaya organisasi diharapkan karyawan lebih memiliki rasa bangga dan nyaman berada di perusahaan. Hal ini dapat dilakukan dengan cara perusahaan memelihara karyawan dengan memberikan kompensasi yang sesuai agar karyawan merasa nyaman dan tetap berada di perusahaan.

4. Perusahaan perlu meningkatkan komitmen organisasi yang ada pada diri karyawan. Hal ini dapat dilakukan dengan membuat karyawan merasa memiliki dan dibutuhkan organisasi, yaitu dengan memberi otonomi karyawan dalam menata ruang kerjanya, mengikutsertakan karyawan dalam keputusan penting mengenai pengefektifan kinerja. Selain itu membuat karyawan merasa dihargai dan dibutuhkan, yaitu dengan cara menghargai hasil kerjanya dengan pemberian reward maupun promosi jabatan.

5. Karyawan lebih meningkatkan dan lebih menaati peraturan perusahaan, dengan datang bekerja dengan tepat waktu dan tidak mendahului pulang yang tidak sesuai dengan jam kerja yang diterapkan perusahaan sehingga menunjukan karyawan yang memiliki loyalitas tinggi untuk membantu mencapai tujuan perusahaan. Dan perusahaan memberikan reward ataupun punishment kepada karyawan telah taat terhadap peraturan maupun kepada karyawan yang telah melanggar peraturan perusahaan. 
6. Perusahaan harus lebih memperhatikan prestasi kerja karyawannya, dengan cara melakukan melakukan penilaian prestasi hasil kerja karyawan setiap periode atau dalam jangka waktu tertentu agar perusahaan dapat menilai apakah prestasi hasil kerja karyawan sudah sesuai dengan harapan perusahaan yang nantinya akan bermanfaat bagi kemajuan karyawan dan khususnya perusahaan.

\section{Saran Peneliti Selanjutnya}

1. Bagi peneliti selanjutnya diharapkan untuk meneliti variable lain yang tidak diteliti dalam penelitian ini yang berpengaruh terhadap prestasi kerja.

\section{DAFTAR PUSTAKA}

\section{Sumber Buku}

Abdullah, M. Ma'ruf, 2014, "Manajemen dan Evaluasi Kinerja Karyawan”., Sleman, Yogyakarta; Aswaja Pressindo

Badriyah, M. 2015. "Manajemen Sumber Daya Manusia”. Cetakan Kesatau. Bandung; CV Pustaka Setia.

Badriyah, M., \& Affifudin. 2015. "Manajemen Sumber Daya Manusia”. Bandung; Pustaka Setia.

Dharma, Surya dalam Usmara ed, 2010, "Manajemen Kinerja, Falsafah, Teori, dan Penerapannya". Yogyakarta; Pustaka Pelajar.

Gede, Wayan Supartha \& Desak Ketut Sintaasih. 2017. "Pengantar Perilaku Organisasi”. Denpasar; CV. Setia Bakti.

Hamali, Arif Yusuf. 2016. "Pemahaman Manajemen Sumber Daya Manusia". Edisi Pertama. Yogyakarta; CAPS (Center For Academic Publishing Service).

Hasibuan, Malayu. 2011. "Manajemen Dasar, Pengertian, Dan Masalah". Edisi kesembilan. Jakarta; Bumi Aksara Jakarta; PT Bumi Aksara.

Mangkunegara, Anwar Prabu. 2017. "Manajemen Sumber Daya Manusia Perusahaan”. Bandung; PT Remaja Rosdakarya.

Refika Aditama.

Marwansyah. 2012. "Manajemen Sumber Daya Manusia". Edisi Kedua. Bandung; Alfabeta CV.

Maslow, Abraham. H. 2013. "Motivasi dan Kepribadian (Teori Motivasi dengan Pendekatan Hierarki Kebutuhan Manusia)". Jakarta; PT PBP 
Nawawi, Hadari. 2011. ”Manajemen Sumber Daya Manusia Untuk Bisnis Yang Kompetitif'. Yogyakarta; Gadjah Mada University Press.

Priansa, Juni Donni. 2018. "Perencaan \& Pengembangan SDM". Bandung; Alfabeta

Priyono dan Marnis. 2008. "Manajemen Sumber Daya Manusia”. Taman Sidoarjo; Zifatama Publisher

Ravianto. J. 2005. "Produktivitas dan Manajemen Sumber Daya Manusia Edisi Revisi 1”. Jakarta; Lembaga Sarana Informasi dan Produktivitas.

Ridwan dan Kuncoro. 2014. "Cara Menggunakan dan Memaknai Path Analysis (Analisis Jalur)". Cetakan keenam. Bandung; Alfabeta.

Robbins, Stephen P., dan Coulter, Mary. 2010. "Manajemen, Edisi Kesepuluh jilid 2". Terjemahan oleh Bob Sabran dan Devri Bernadi Putera. Jakarta; Erlangga.

Sugiyono. 2012. "Metode Penelitian Kualitatif Kuantitatif dan R\&D”. Bandung; Alfabeta

Sunyoto, Danang. 2013. "Manajemen Sumber Daya Manusia”. Edisi 2. Yogyakarta; CAPS (Center For Academic Publishing Service).

Suparyadi. 2015. "Manajemen Sumber Daya Manusia”. Edisi 1. Yogyakarta; Andi.

Sutrisno, Edy. 2016. "Manajemen Sumber Daya Manusia”. Edisi Kedelapan. Jakarta; Kencana.

Sutrisno, Edy. 2012. "Manajemen Sumber Daya Manusia”. Jakarta; Kencana Prenada Media Group.

Sutrisno, Edy. 2014. "Manajemen Sumber Daya Manusia” . Edisi Keenam. Jakarta; Prenada Media Group.

Umam, Khaerul. 2012. "Perilaku Organisasi”. Bandung; CV Pustaka Setia.

Wahjono, Imam Sentot. 2015. "Manajemen Sumber Daya Manusia". Jakarta; SalembaEmpat.

Wibowo. 2017. "Manajemen Kinerja”. Edisi Kelima. Depok; PT. Raja Grafindo Persada.

Buku Pedoman Penyusunan Tugas Akhir Mahasiswa S1 Manajemen. 2017. Fukultas Ekonomi dan Bisnis Universitas Singaperbangsa Karawang

\section{SUMBER PENDUKUNG}

\section{Skripsi}

Kinerja Karyawan Rumah Sakit Islam Karawang”

Said Tedy Murdani (Skripsi, 2015) "Pengaruh Kompetensi dan Motivasi Kerja Terhadap Prestasi Kerja Pegawai di Dinas Pendapatan, Pengelolaan Keuangan dan Aset Daerah Kabupaten Karawang" 
Dwi Chandra Lingga (Skripsi, 2018) "Pengaruh Motivasi dan Disiplin Kerja Terhadap Prestasi Kerja Pegawai Pada Dinas Kesejahteraan dan Sosial Provinsi Sumatera Utara"

Mahendra (skripsi, 2005) "Pengaruh Sikap Kerja Terhadap Prestasi Kerja Karyawan Suara Merdeka Semarang"

\section{Jurnal}

Afni Can dan Yasri. 2013. Pengaruh Motivasi Kerja, Kepuasan Kerja, dan Komitmen Organisasi Terhadap Kinerja Karyawan Pada Bank Nagari.

John, Theodora Yatipai, Sonny Gerson Kaparang. 2015. Pengaruh Motivasi Terhadap Prestasi Kerja Karyawan Pada PT Pos Indonesia Tipe C Manado. Jurnal Administrasi Bisnis, 2014.

Salju dan Mastia Makmur. 2014. Pengaruh Motivasi dan Komitmen Organisasi Terhadap Prestasi Kerja Karyawan Pada PT Marina Putra Indonesia Perwakilan Kabupaten Luwu Utara. Jurnal Manajemen Vol. 01 No. 02.

Komang Joni Udayana. 2015. Pengaruh Komitmen Organisasi Terhadap Prestasi Kerja Karyawan PT Sekara Nusa Baruna Cabang Singaraja. Vol:5 Nomor: 1 Tahun: 2015 